\title{
How Can Reading Comprehension Strategies and Recall Be Improved in Elementary School Students?
}

\author{
¿Cómo pueden mejorarse las estrategias de \\ comprensión y el recuerdo textual en estudiantes \\ de primer curso de Educación Primaria?
}

\section{CALIXTO GUTIÉRREZ- BRAOJOS \\ Universidad de Granada \\ calixtogb@ugr.es}

\author{
SONIA RODRÍGUEZ \\ FERNÁNDEZ \\ Universidad de Granada \\ soniarf@ugr.es
}

\author{
PURIFICACIÓN \\ SALMERÓN-VÍLCHEZ \\ Universidad de Granada \\ psalmero@ugr.es
}

\begin{abstract}
The purpose of this article was to analyze whether students in the first grade of primary school who were taught using a direct instruction method improved their use of reading comprehension strategies and their text recall. The participants were 48 firstcourse Primary School students. The design was quasiexperimental with a pretest and two posttest measures in both groups (control and experimental). The instrument applied to collect the data was the Contextualized Scale for the Evaluation of Learning Strategies. The findings favor direct instruction in first course. Thus, in the majority of the students who participated in our direct instruction method, the results showed an improvement in reading comprehension strategies and text recall.
\end{abstract}

Keywords: reading comprehension strategies; recall; direct instruction; elementary school.
Resumen: La meta de este artículo fue analizar si los estudiantes de primer grado pueden mejorar sus estrategias de comprensión lectora y recuerdo del texto desde el enfoque de la instrucción directa. Los participantes fueron 48 estudiantes matriculados en primero de Educación Primaria. El diseño fue cuasi-experimental (pretest y dos postest con un grupo control). El instrumento aplicado para recoger los datos fue la escala de evaluación contextualizada de estrategias de aprendizaje. Los resultados indicaron que la mejora en estrategias de comprensión y recuerdo del texto de la mayoría de los estudiantes del grupo que recibió la intervención de instrucción directa fue mayor que la del grupo de control.

Palabras clave: estrategias de comprensión lectora; recuerdo textual; instrucción directa; educación primaria. 


\section{INTRODUCTION}

$\mathrm{D}$ uring recent decades, some of the efforts made in educational research in compulsory education have had the goal of understanding and improving the processes involved in students' reading competence. The purpose of reading competence is to construct a representation of the text that allows the reader to respond to different demands. To do so, in addition to decoding processes, it is necessary to activate a set of reading comprehension strategies that facilitate the representational construction of a text. Recent empirical evidence shows that the use of comprehension strategies contributes to reading performance (e.g. Gutiérrez-Braojos, \& Salmerón-Pérez, 2012; Smith, Borkowski, \& Whitman, 2008). In this sense, various researchers suggest that the most effective way to teach students to build a textual representation is through explicit instruction in comprehension strategies (e.g. Block \& Pressley, 2002). In fact, both the use of comprehension strategies and reading performance seem to be associated with the strategic quality of the instructional practices used to teach reading competence (Connor, et al., 2010).

However, several reports on reading (e.g. National Reading Panel, NRP; and National Research Council: Preventing reading difficulties in young children) indicate a low percentage of studies designed to facilitate the internalization of comprehension strategies in the primary grades. According to various authors (e.g. Paris \& Paris, 2007; Strasser \& Lissi, 2009), in the lower elementary grades, the majority of the empirical studies have focused on decoding and reading fluency processes, leaving out reading comprehension strategies to a large degree. Likewise, recent studies designed to analyze instructional practices for text comprehension conclude that teachers do not dedicate enough time to teaching strategies that can facilitate the reader's textual comprehension, focusing instead on improving decoding and reading fluency processes (e.g. Pearson \& Duke, 2002; Taylor, Peterson, Pearson, \& Rodriguez, 2002). This tendency, observed both in teaching and research, could be mainly rooted in beliefs about the development and teaching of learning strategies that must be addressed.

The first belief is that the metacognitive processes do not emerge until 8 to 10 years of age (e.g. Flavell, 1987; Veenman \& Spaans, 2005). For example, Chall (1967, 1996, cited by Paris \& Hamilton, 2009) created a stage model of reading development consisting of six stages. Chall s model underestimates the students' comprehension capacities by stating that during the first four stages (until 4th-8th grades) the students only develop their decoding skills. However, empirical studies show that before the age of 6 , children show self-regulated speech and behaviors that demonstrate the use of planning, monitoring-control and evaluation strategies 
(Balcomb \& Gerken, 2008; Bronson, 2000; Bull, Espy, \& Wiebe, 2008; Garner \& Bochna, 2004; Whitebread \& Basilio, 2012).

The second belief holds that the capacity for comprehension requires the prior acquisition of decoding skills and a certain degree of reading fluency. We agree with Paris and Paris, (2007) when they state that: because comprehension is a complex process that requires effort and is developed independently from decoding, all children in early elementary grades need explicit instruction in strategies according to the discourse genre (p. 5). Specifically regarding comprehension tasks, recent studies show that from the age of three or four, school children use causal and predictive inferences and are capable of constructing a mental representation of a narrated story, regardless of the level of their decoding skills (Kendeou, van den Broek, \& White, 2009; van den Broek et al. 2005).

As a result of the aforementioned beliefs, a third belief would be that comprehension strategies cannot be taught at elementary levels before the age of 8 . However, there is evidence that these students show sufficient levels of cognitive flexibility and attentional and inhibitory control, helping them to adapt their behavior to the demands of school (Cartwright, 2012).

Therefore, a low level of decoding skills cannot be a reason to avoid the need to develop reading comprehension strategies in early primary education. Both types of skills, reading and strategic, are associated with the quality of the educational practices used for this purpose (Ponitz et al., 2008).

\section{Reading comprehension strategies, recall and reading competence}

The reading comprehension strategies are conscious, deliberate and flexible psychological tools selected by readers to efficiently guide, control, supervise and evaluate the coherent representational construction of a text (Gutiérrez-Braojos \& Salmerón-Pérez, 2012).

Although reading comprehension strategies intervene in cognitive-metacognitive, voluntary and affective-emotional processes (Dole, Nokes, \& Drits, 2009), in this study we focus on cognitive and metacognitive strategies. We consider the cognitive strategies to be conscious activities involved in correcting or avoiding comprehension mistakes during the bottom-up and top-down processes followed in the representational construction of a text. Therefore, the strategies that facilitate the bottom-up processes are mainly linked to the ascendant reading process, starting from the most basic textual elements, such as grapheme to phoneme conversion. Among them we find strategies such as identifying unknown words. On the other hand, the top-down strategies facilitate processes of linking prior knowledge, 
the text and the context, and they include predictions, inferences, self-questions, etc. (Paris \& Paris, 2007).

The metacognitive strategies refer to the activation of relevant knowledge and bidirectional operations of guiding and monitoring-controlling the activity (Efklides \& Misailidi, 2010). Through these strategies, the learner tries to work efficiently toward a goal, according to the task characteristics and the learning situation. From this point of view, a competent strategic reader is one who has knowledge about when and why to use one strategy or another, depending on the reading purpose, and shows skill in applying the strategies by means of monitoring and control processes.

The contribution of the reading comprehension strategies to reading competence has been shown in studies carried out from different scientific disciplines. From the field of neuropsychology, various studies have analyzed the role of the executive function in comprehension, comparing novice and expert readers. The results show that, unlike expert readers, poor readers demonstrate problems in planning and inhibition of irrelevant information (e.g. Sesma, Mahone, Levine, Eason, \& Cutting, 2009; Welsh, Nix, Blair, Bierman, \& Nelson, 2010). Recently, Booth, Boyle and Kelly (2010) carried out a meta-analysis with a total of 48 studies. They found sufficient evidence to support a close contribution of processes involved in the executive function (meta-cognition), specifically between cognitive flexibility, recall, and reading competence.

Likewise, from the field of educational psychology, a sufficient body of research has comparatively analyzed, in novice and expert readers, the relationship between the use of comprehension strategies and reading performance. According to these studies, students who are experts in reading comprehension usually use comprehension strategies flexibly, while those with comprehension difficulties use comprehension strategies very little and in an inflexible way (e.g. Paris, Wasik, \& Turner, 1991), making them incapable of activating appropriate prior knowledge (e.g. Marr \& Gormley, 1982), building a structured representation of the text (e.g. Dermitzaki, Andreou, \& Paraskeva, 2008), making inferences (e.g. Winne, Graham, \& Prock, 1993), or using metacognitive knowledge (e.g. Mayer, 2002; Eme, Puustinen, \& Coutelet, 2006) to achieve more efficient performance on text recall (e.g. Horner \& O Connor, 2007).

In sum, based on the body of research presented, we can state that the use of reading comprehension strategies is a major characteristic of competent readers. 


\section{Teaching Comprehension Strategies: Direct Instruction}

Reading comprehension strategies are taught in order to help students to internalize (Vygotsky, 1978) the psychological tools of monitoring-control and efficient construction of their own textual representations. Through the direct instruction approach (DIA), teachers can facilitate students' internalization of reading comprehension strategies that can improve reading comprehension and recall ( $\mathrm{McKe}-$ own, \& Beck, 2009; Ruplay, Blair, \& Nichols, 2009). DIA is a teaching approach characterized by explicit and step-by-step instruction (Rosenshine \& Stevens, 1986).

Pearson and Gallagher (1983, in Pearson, 2009) developed a dynamic model of the teacher's role. This model consists of three phases. In the first phase, the students are still incapable of spontaneously using the learning strategies. Thus, explicit instruction is advisable, where the responsibility for performing the tasks falls on the teacher. In this phase, the teacher helps the students to learn what, how, when and why to use the strategies, by means of modeling and thinking aloud. In the second phase, there is a shared responsibility for doing a task and using the strategies, aided by guided practice and applying scaffolding. And in the third phase, when the students spontaneously use strategies, the teacher reduces the application of scaffolding in order to foster greater responsibility in using strategies and doing the task.

Empirical studies that have analyzed the efficacy of instruction for the internalization of reading comprehension strategies at the most elementary levels have yielded contradictory results. Some studies have concluded that these programs produce beneficial results (e.g. Block, Parris, \& Whiteley, 2008; Brenna, 1995; Brown, Pressley, van Meter, \& Schuder, 1996; Connor, et al., 2010; Dignath, Buettner, \& Langfeldt, 2008; Eliers \& Pinkley, 2006; Gardner \& Bochna, 2004; Juliebö, Malicky, Norman, 1998; Kinnunen, Vauras, \& Neimi, 1998), while other studies, relatively similar to these, have not found a significant improvement in beginning readers (e.g. Rosenshine, Meister \& Chapman, 1996). Therefore, various authors suggest the possibility that training in learning strategies interferes more than it helps in reading comprehension processes, by overloading the working memory (e.g. Fuchs \& Fuchs, 2007).

However, recent studies have implemented programs for developing comprehension strategies using wordless picture books or televised narrations with children from the age of four (e.g. Kendeou et al., 2009; Paris \& Paris, 2003). These studies are mainly based on three aspects: i) from the age of three on, children have developed considerable knowledge about narrative stories (Paris \& Paris); ii) narrative picture books and narrative texts make similar cognitive demands (e.g. knowledge about the elements of a story, inferences, comprehension of time and causal se- 
quences) (Paris \& Paris, 2007); iii) the scientific belief that comprehension skills are independent from decoding skills and predict reading comprehension (van den Broek et al. 2005). The results of these studies conclude that these programs are effective and lead to improved reading comprehension.

Therefore, based on the body of research presented, students enrolled in the first grade of primary education can be taught to improve their comprehension strategies and text recall.

\section{The Present Study}

The purpose of this article was to analyze whether students in the first course of primary school who were taught using direct instruction improved their use of reading comprehension strategies and their text recall.

\section{METHOD}

\section{Participants}

The participants were 48 first-course Primary School students (57.8 \% girls; 42.2 $\%$ boys; age range from 6 to 8 years) from a school in Andalusia (Spain). The school was chosen intentionally and with the cooperation of an education inspector in the area, using mainly the following criteria: i) it had to guarantee a high involvement of the teachers in the instructional proposal; ii) in the previous course the students had to have worked on the decoding processes involved in reading comprehension.

Taking the class group as the unit, one class was randomly assigned to the experimental group $(n=25)$ and the other to the control group $(n=23)$. With the experimental group, a set of specific instructional materials were used to teach them learning strategies for reading comprehension tasks.

\section{Design}

To reach the objective, a quasi-experimental design was used with a pretest and two posttests in both groups (control and experimental). The pretest measurement was performed at the beginning of the second term of the school year, while the posttest measures were obtained at the end of the second and third terms. Thus, the first posttest has a monitoring purpose, as the program is still on-going, while the second posttest is applied at the end of the school year, just after the program ends. 


\section{Instruments}

To evaluate the competence in narrative comprehension, the scale selected and applied was the Contextualized Scale of Learning Strategies on Reading Comprehension Tasks, (Escala de Estrategias de Aprendizaje Contextualizado, ESEAC, Bernad, 2000). The ESEAC is a contextualized evaluation test (test-protocol) of the learning strategies in a specific domain (e.g. text comprehension). The test consists of solving a task and formulating set questions related to reading comprehension strategies and recall during and after performing the task, i.e., reading a text. In this sense, the ESEAC helps the evaluator to gather information by observing the task and through the strategic thinking explained by the student evaluated. To evaluate each of the variables, Bernad provides instructions that, in place of questions, invite the student to describe their specific form of strategic thinking when faced with a task in situ (see Bernad). The ESEAC scores the level of strategic thinking as " $1=$ low level of strategic thought"; " $2=$ medium level of strategic thought; " $3=$ high level of strategic thought"). The students' written and oral responses and their performance on the task allow the evaluator to place them in one of these three levels. The reading comprehension strategies were the following:

- Comprehension of the task demands and planning: refers to the students' command of the relevant knowledge for comprehending and interpreting the task, including framing it within a context, i.e. the student establishes strategic steps for reading the text.

- Hypothesis: In this context, refers to the quality of the predictions made by the students based on the illustrations and the title.

- Representation of iconic and verbal languages: the student's representations of the knowledge using each of the following codes:

- Iconic language corresponds to the student's capacity to graphically represent the text;

- Verbal language corresponds to the ability to elaborate a summary of the text.

- Inferences: Deduce something or draw a conclusion based on what is directly available, in other words, implicit comprehension.

- Typical doubts: Doubts that arise during the task and the student's ability to be aware of them and resolve them correctly, corresponding to Monitoringcontrol while performing the task.

- Evaluation: The student's awareness of his/her level of command of the task and possible problems encountered while doing the task. 
- On the other hand, apart from the ESEAC, textual recall was evaluated based on the percentage of recall of the textual grammar and its contents ( $80 \%$ or more, level " 3 " for recall; $50 \%$ or less corresponds to a low level of recall; the remaining percentage was considered the middle level. For this purpose, reactive questions were posed based on: the framework of the story and characters (e.g. Who is the story talking about? At what time of year does this story take place?); Initial event-problem-event (e.g. where did he fall asleep...? What happened to the lake while...?); the outcome event (How did he help...?).

This scale has been applied in diverse studies, obtaining satisfactory results with regard to reliability, internal validity and external validity (e.g. Bernad, 2000).

The text had similar features (e.g. length, difficulty, graphics, and font size) to those worked on in class using the official reading textbook. The validation of the difficulty of the texts used in the ESEAC test was carried out by expert judges (10 primary school teachers) in the previous phase. For this purpose, they used a Likert scale that ranged from 1 to 4 , where 1 is interpreted as completely inappropriate, and 4 as completely appropriate. The results indicate that all the experts considered the texts completely appropriate.

In this study, the ESEAC evaluation procedure and the students' results did not have interjudge reliability due to lack of resources (number of evaluators) and time. However, in order to ensure the validity of the application of the instrument, the evaluators were instructed in its correct use. Three of the evaluators were licensed in educational psychology and worked as teachers in different schools, and one was a doctoral student. The training consisted of three sessions lasting approximately one hour each (see Table 1). The test was applied individually in a room in the school outside the students' corresponding classrooms. Furthermore, testers were not aware of treatment assignments.

\section{Table1: Training sessions for the evaluators}

SESSIONS Objectives of the sessions

SESSION I Introductory explanation of the study: objectives and instruments

SESSION II $\quad$ Practice I: Observation of the application of the instruments and clarification of doubts about the application procedure

SESSION III Practice II: Pilot application of the ESEAC with supervision by the expert and, once applied, clarification of any doubts that arose during the application process. 


\section{Procedure: Instructional Program}

The purpose of the instructional program is to teach the students a specific set of cognitive and metacognitive reading comprehension strategies using narrative texts. The cognitive strategies were: predictions based on the title and visual representations of the text, inferences, elaboration of graphic organizers of the textual structure, and summaries. Regarding the metacognitive strategies, instruction was given in the strategies of: comprehension and planning, control-monitoring, and evaluation of their own reading performance.

The program consists of a teachers' manual and a workbook. The teachers' manual contains two parts, a theoretical section about the reading comprehension strategies, and a teaching guide for the instructional application of the workbook with the students. The workbooks were organized in the form of guidelines and included questions that, used as prompts, facilitated the students' strategic reading of the texts from the official reading textbook used in the school. These guidelines were presented by a fictitious character in the workbook. This character played the role of a co-instructor (with the teacher) who: i) facilitated the students' understanding of the activity goal; ii) briefly explained what strategy could be used; and iii) explained when it would be useful. Thus, this fictitious character was utilized as a resource to support the teacher's explanation.

The program consisted of 7 lessons taught during 16 weeks (Table 2). Each lesson was designed to teach a maximum of two comprehension strategies, and it was applied four times each week. The first lesson consisted of introducing the students to the narrative texts, their characters and structural sequence, the guidance material, and the procedure for doing the reading tasks. In this way, the intention was for the students to begin to become familiar with the procedure and the new work material (duration: one week). The second lesson included the cognitive strategy of prediction. The teachers helped the students to use the title of the text and the illustrations as a resource to predict the content of the text. After the joint reading of the text, the teacher dialogued about how precise the predictions were (duration: two weeks). The third lesson had the purpose of teaching the students the metacognitive strategy of control-monitoring. The students read each paragraph and had to detect difficulties in comprehending words, sentences, or the main idea of each paragraph, and these difficulties were later clarified by the whole class (duration: two weeks). The fourth lesson was directed toward teaching two cognitive strategies: the use of visual representations to organize the structure of the text and the content of the narration (graphic organizers); and summarizing each visual representation (duration: three weeks). The fifth lesson consisted of teaching the cogni- 
tive strategy called inferences, with the purpose of deducing information not contained in the text, based on prior knowledge and other information contained in the text (duration: two weeks). The sixth lesson was designed to teach metacognitive strategies of evaluation regarding: i) level of textual comprehension; and ii) awareness of the different individual difficulties encountered while reading the text (duration: two weeks). Finally, the seventh lesson consisted of teaching the students the strategy of planning. In the seventh lesson, the teacher taught the students how to make a reading plan of the steps involved while reading a short narrative text, which are: activate prior knowledge to make predictions based on the title and picture clues; read the text in a general way to detect possible comprehension problems (unknown words, complex sentences); use the inference strategy to try to correct these comprehension problems; make a visual representation of the different narrative passages according to what happens to the different characters in the story, and summarize each paragraph, extracting the most relevant information in the narration; and evaluate the level of comprehension and the difficulties during the reading process (duration: four weeks).

\section{Table 2. Phases of the program to facilitate the internalization of the reading comprehension}

\begin{tabular}{lcl} 
LESSONS & WEEK & PHASE OF STRATEGIC PERFORMANCE \\
\hline Lesson 1: Introduction & 1 & Explicit instruction: Introduction to narrative texts. \\
\hline Lesson 2: Prediction & 2 & $\begin{array}{l}\text { Explicit instruction (what, how, when and why to use the } \\
\text { prediction strategy) modeling, and guided practice of the } \\
\text { strategy and applying scaffolding. }\end{array}$ \\
\cline { 2 - 3 } & 3 & Teacher reduces the application of scaffolding. \\
\hline Lesson 3: & 4 & $\begin{array}{l}\text { Explicit instruction (what, how, when and why to use the } \\
\text { monitoring strategy) modeling, and guided practice of the } \\
\text { strategy and applying scaffolding. }\end{array}$ \\
\cline { 2 - 3 } $\begin{array}{l}\text { Lesson 4: } \\
\text { Visual representations }\end{array}$ & 5 & $\begin{array}{l}\text { Teacher reduces the application of scaffolding. } \\
\text { \& summarizing }\end{array}$ \\
\cline { 2 - 3 } & 7 & $\begin{array}{l}\text { Explicit instruction (what, how, when and why to use the } \\
\text { strategies) modeling, and guided practice of the strategy } \\
\text { and applying scaffolding. }\end{array}$ \\
\cline { 2 - 3 } & 8 & $\begin{array}{l}\text { Guided practice of the strategy and applying scaffolding. } \\
\text { Teacher reduces the application of scaffolding. }\end{array}$ \\
\hline
\end{tabular}




\begin{tabular}{|c|c|c|}
\hline LESSONS & WEEK & PHASE OF STRATEGIC PERFORMANCE \\
\hline \multirow[t]{2}{*}{$\begin{array}{l}\text { Lesson 5: } \\
\text { Inferences }\end{array}$} & 9 & $\begin{array}{l}\text { Explicit instruction (what, how, when and why to use the } \\
\text { inferences strategy) modeling, and guided practice of the } \\
\text { strategy and applying scaffolding. }\end{array}$ \\
\hline & 10 & Teacher reduces the application of scaffolding. \\
\hline \multirow{3}{*}{$\begin{array}{l}\text { Lesson 6: } \\
\text { Evaluation strategies }\end{array}$} & 11 & Explicit instruction (what, how, when and why to use the \\
\hline & & $\begin{array}{l}\text { Evaluation strategy) modeling, and guided practice of the } \\
\text { strategy and applying scaffolding. }\end{array}$ \\
\hline & 12 & Teacher reduces the application of scaffolding. \\
\hline \multirow[t]{4}{*}{$\begin{array}{l}\text { Lesson 7: } \\
\text { Planning }\end{array}$} & 13 & $\begin{array}{l}\text { Explicit instruction (what, how, when and why to use the } \\
\text { planning strategy) modeling, and guided practice of the } \\
\text { strategy and applying scaffolding. }\end{array}$ \\
\hline & 14 & Guided practice of the strategy and applying scaffolding. \\
\hline & 15 & Guided practice of the strategy and applying scaffolding.. \\
\hline & 16 & Teacher reduces the application of scaffolding. \\
\hline
\end{tabular}

\section{Analytical strategy and data analysis}

To respond to the study objective, "Analyze the efficacy of the intervention program", the following analytical strategy was used:

- Comparative intergroup analysis of the associated means of each group at all the evaluation points, in order to discover significant differences between the experimental and control groups.

- Comparative analysis between the pretest and the different posttests to discover the improvement in each group (experimental and control) on the study variables.

- Given that there was an absence of normality in a large number of variables, and the sample size was small, we considered it appropriate to apply MannWhitney $\mathrm{U}$ tests and the Wilcoxen $W$ to respond to the study questions.

- Likewise, the effect size was calculated by means of Hedges $g$. To do so, the Internet program for calculating effect sizes was used (Ellis, 2009). The results were interpreted based on suggestions by Cohen (1988, cited in FernándezCano, \& Fernández Guerrero, 2009).

The data were analyzed using the computer program SPSS 18 for Windows. 


\section{RESULTS}

\section{Efficacy of the instructional materials for developing comprehension strategies}

The results indicate that the students showed a certain level of internalization of comprehension strategies only at the end of the school year, where the improvement in the experimental group was significantly superior to that of the control group. However, the results show that the students in the experimental group reached a medium-level use of comprehension strategies. Next, we present the results in greater detail.

\section{Intra-group comparison at the different evaluation points}

This section presents the data obtained on the comparison between the pretest and the different posttests of each group.

\section{Improvement of the Control Group during the school year}

The application of the Wilcoxen $W$ test (Table 3 ) for the pretest-posttest 1 comparative analysis showed significant differences on strategies of inference comprehension $(Z=-2.449 ; p<.05)$, control-monitoring $(Z=-2.754 ; p<.05)$, Graphical representation $(Z=-2.428 ; p<.05)$, self-evaluation $(Z=-2.236 ; p<.05)$, and recall $(Z=-2.296 ; p<.05)$. Nonetheless, except on the monitoring variable where the effect was high $(g=.80)$, in the rest of the cases where significant differences were observed, the effect size was moderate ( $g$ values between $g=.59$ and $g=.73$ ). In any case, on the first posttest, all the students showed a low level on all the study variables.

\section{Table 3: Control Group: Pretest-Posttest 1 comparison applying the Wilcoxen W test}

\begin{tabular}{lccccccccc}
$\begin{array}{l}\text { DEPENDENT } \\
\text { VARIABLES }\end{array}$ & $\begin{array}{c}\text { PRETEST } \\
(\mathrm{n}=23)\end{array}$ & \multicolumn{2}{c}{$\begin{array}{c}\text { POSTTEST } \\
(\mathrm{n}=23)\end{array}$} & \multicolumn{7}{c}{ ASSOCIATED STATISTICAL VALUES } \\
\cline { 2 - 11 } & $\mathrm{X}$ & $\mathrm{SD}$ & $\mathrm{X}$ & $\mathrm{SD}$ & $\sum \mathrm{R}^{\circ}(-)$ & $\sum \mathrm{R}^{\circ}(+)$ & $\mathrm{Z}$ & $\mathrm{P}$ & $\mathrm{g}$ \\
\hline Planning & 1.12 & .33 & 1.18 & .43 & 4 & 1 & -.966 & .334 & .15 \\
\hline Predictions & 1.08 & .27 & 1.16 & .37 & 2.5 & 7.5 & -1.000 & .317 & .24 \\
\hline Inferences & 1.04 & .10 & 1.28 & .54 & 0 & 21 & -2.449 & .014 & .60 \\
\hline Monitoring & 1.12 & .23 & 1.52 & .65 & 7 & 71 & -2.754 & .006 & .80 \\
\hline
\end{tabular}




\begin{tabular}{lccccccccc}
$\begin{array}{l}\text { DEPENDENT } \\
\text { VARIABLES }\end{array}$ & $\begin{array}{c}\text { PRETEST } \\
(\mathrm{n}=23)\end{array}$ & \multicolumn{2}{c}{$\begin{array}{c}\text { POSTTEST } \\
(\mathrm{n}=23)\end{array}$} & \multicolumn{7}{c}{ ASSOCIATED STATISTICAL VALUES } \\
\cline { 2 - 11 } & $\mathrm{X}$ & $\mathrm{SD}$ & $\mathrm{X}$ & $\mathrm{SD}$ & $\sum \mathrm{R}^{\circ}(-)$ & $\sum \mathrm{R}^{\circ}(+)$ & $\mathrm{Z}$ & $\mathrm{P}$ & $\mathrm{g}$ \\
\hline Graphical R. & 1.08 & .27 & 1.48 & .71 & 0 & 28 & -2.428 & .015 & .73 \\
\hline Summary & 1.32 & .48 & 1.36 & .63 & 30 & 36 & -.284 & .776 & .07 \\
\hline Evaluation & 1.04 & .20 & 1.24 & .43 & 0 & 15 & -2.236 & .025 & .59 \\
\hline Recall & 1.24 & .52 & 1.68 & .80 & 18 & 87 & -2.296 & .022 & .64 \\
\hline
\end{tabular}

The pretest-posttest 2 (Table 4) comparative analysis showed significant differences in favor of the posttest on all the variables except planning $(Z=-1.827 ; p>.05)$ and summary $(Z=-1.662 ; p>.05)$. Furthermore, a moderate effect size is observed on the variables planning $(g=.44)$ and summary $(g=.52)$. The rest of the variables showed a high or somewhat high effect size. However, it is important to mention that the means of the control group on the posttest indicate that the levels of comprehension strategies (metacognitive and cognitive) and performance are relatively low. Therefore, we consider that the students showed a slow progression on the study variables.

Table 4: Control Group: Pretest-Posttest 2 comparison applying the Wilcoxen W test

\begin{tabular}{lccccccccc}
$\begin{array}{l}\text { DEPENDENT } \\
\text { VARIABLES }\end{array}$ & $\begin{array}{c}\text { PRETEST } \\
(\mathrm{n}=23)\end{array}$ & \multicolumn{2}{c}{$\begin{array}{c}\text { POSTTEST } \\
(\mathrm{n}=23)\end{array}$} & \multicolumn{7}{c}{ ASSOCIATED STATISTICAL VALUES } \\
\cline { 2 - 12 } & $\mathrm{X}$ & $\mathrm{SD}$ & $\mathrm{X}$ & $\mathrm{SD}$ & $\sum \mathrm{R}^{\circ}(-)$ & $\sum \mathrm{R}^{\circ}(+)$ & $\mathrm{Z}$ & $\mathrm{P}$ & $\mathrm{g}$ \\
\hline Planning & 1.12 & .33 & 1.38 & .66 & 10 & 45 & -1.827 & .068 & .49 \\
\hline Predictions & 1.08 & .27 & 1.48 & .71 & 9 & 57 & -2.233 & .026 & .73 \\
\hline Inferences & 1.04 & .10 & 1.40 & .70 & 3 & 33 & -2.165 & .030 & .71 \\
\hline Monitoring & 1.12 & .23 & 1.68 & .74 & 24 & 112 & -2.428 & .015 & 1 \\
\hline Graphical R. & 1.08 & .27 & 1.52 & .77 & 8 & 58 & -2.229 & .022 & .75 \\
\hline Summary & 1.32 & .48 & 1.64 & .70 & 32.5 & 87.5 & -1.662 & .096 & .52 \\
\hline Evaluation & 1.04 & .20 & 1.44 & .76 & 2.5 & 33.5 & -2.226 & .026 & .71 \\
\hline Recall & 1.24 & .52 & 1.76 & .83 & 28 & 108 & -2.132 & .033 & .74
\end{tabular}

Finally, a more detailed review of the data in both tables (Tables 3 and 4) shows a common pattern: the improvement on the posttest means is linked to an increase in the standard deviation. 
Improvement in the Experimental Group during the school year

The application of the Wilcoxen $W$ test regarding the pretest-posttest 1 comparative analysis showed significant differences on all the variables about comprehension strategies and on recall. On the other hand, on the first posttest, the students showed a low level on the majority of the study variables, except on planning, predictions, monitoring-control and recall, which approach a medium level (Table 5). Regarding the significant variables, the effect size observed is high, except in summary $(g=.44)$.

Table 5: Experimental Group: Pretest-Posttest 1 Comparison applying the Wilcoxen W test

\begin{tabular}{|c|c|c|c|c|c|c|c|c|c|}
\hline \multirow[t]{2}{*}{$\begin{array}{l}\text { DEPENDENT } \\
\text { VARIABLES }\end{array}$} & \multicolumn{2}{|c|}{$\begin{array}{l}\text { PRETEST } \\
(n=25)\end{array}$} & \multicolumn{2}{|c|}{$\begin{array}{c}\text { POSTTEST } \\
(n=25)\end{array}$} & \multicolumn{5}{|c|}{ ASSOCIATED STATISTICAL VALUES } \\
\hline & $x$ & SD & $x$ & SD & $\Sigma \mathrm{R}^{\circ}(-)$ & $\Sigma \mathrm{R}^{\circ}(+)$ & Z & $\mathrm{p}$ & $g$ \\
\hline Planning & 1.17 & .38 & 1.78 & .59 & 0 & 105 & -3.440 & .001 & 1.21 \\
\hline Predictions & 1.09 & .29 & 1.80 & .60 & 0 & 105 & -3.557 & .000 & 1.48 \\
\hline Inferences & 1.13 & .36 & 1.69 & .82 & 0 & 55 & -2.919 & .004 & .87 \\
\hline Monitoring & 1.09 & .22 & 1.73 & .54 & 0 & 105 & -3.638 & .000 & 1.53 \\
\hline Graphical R. & 1.21 & .51 & 1.61 & .58 & 12 & 66 & -2.324 & .020 & .72 \\
\hline Summary & 1.30 & .47 & 1.52 & .52 & 4 & 24 & -1.890 & .059 & .44 \\
\hline Evaluation & 1.08 & .28 & 1.47 & .51 & 0 & 45 & -3.000 & .003 & .93 \\
\hline Recall & 1.26 & .54 & 1.86 & .69 & 15 & 121 & -2.977 & .003 & .95 \\
\hline
\end{tabular}

Regarding the comparison between the pretest and posttest 2, the Wilcoxen test shows significant differences between all the study variables (Table 6). In these significant variables, the effect size is high. Likewise, with regard to the strategic level of reading comprehension, the experimental group showed a medium level on all the variables. Thus, we can say that the program improved the students' strategic comprehension level and performance, but high levels of the use of strategies were not observed. 
Table 6: Experimental Group: Pretest-Posttest 2 comparison applying the Wilcoxen W test

\begin{tabular}{lccccccccc}
$\begin{array}{l}\text { DEPENDENT } \\
\text { VARIABLES }\end{array}$ & \multicolumn{2}{c}{$\begin{array}{c}\text { PRETEST } \\
(\mathrm{n}=23)\end{array}$} & \multicolumn{2}{c}{$\begin{array}{c}\text { POSTTEST } \\
(\mathrm{n}=25)\end{array}$} & \multicolumn{7}{c}{ ASSOCIATED STATISTICAL VALUES } \\
\cline { 2 - 11 } & $\mathrm{X}$ & $\mathrm{SD}$ & $\mathrm{X}$ & $\mathrm{SD}$ & $\Sigma \mathrm{R}^{\circ}(-)$ & $\sum \mathrm{R}^{\circ}(+)$ & $\mathrm{Z}$ & $\mathrm{p}$ & $\mathrm{g}$ \\
\hline Planning & 1.17 & .38 & 2.28 & .83 & 12 & 219 & -3.665 & .000 & 1.69 \\
\hline Predictions & 1.09 & .29 & 2.13 & .84 & 9 & 162 & -3.435 & .001 & 1.63 \\
\hline Inferences & 1.13 & .36 & 1.90 & .86 & 7 & 98 & -2.944 & .003 & 1.15 \\
\hline Monitoring & 1.09 & .22 & 2.26 & .84 & 15 & 195 & -3.465 & .001 & 1.88 \\
\hline Graphical $\mathrm{R}$. & 1.21 & .51 & 2.21 & .87 & 19.5 & 170.5 & -3.130 & .002 & 1.38 \\
\hline Summary & 1.30 & .47 & 2.35 & .83 & 19.5 & 211.5 & -3.444 & .001 & 1.53 \\
\hline Evaluation & 1.08 & .28 & 1.91 & .90 & 8 & 112 & -3.040 & .002 & 1.23 \\
\hline Recall & 1.26 & .54 & 2.30 & .82 & 21 & 189 & -3.230 & .001 & 1.47 \\
\hline
\end{tabular}

Finally, similar results to those mentioned above for the control group were found for the experimental group. That is, a more detailed review of the data represented in both tables (Tables 5 and 6) indicates that the improvement in the posttest means is related to an increase in the standard deviation.

\section{Comparison between the groups during the application of the program}

The results obtained in the previous section indicate that the reading comprehension strategy program produced significant improvements throughout the school year. To offer a detailed analysis of the gains made by the experimental group compared to the control group, we present a between-group analysis at each evaluation point.

On the pretest, the application of the Mann-Whitney $U$ test and the low magnitude of the effect size show a lack of significant differences between the means of the groups (Table 7).On the other hand, regarding the levels shown by the students on the different study variables, we highlight the low level on the majority of the study variables. 
Table 7: Pretest. Between-groups comparison applying the Mann Whitney U test

\begin{tabular}{lccccccccccc}
$\begin{array}{l}\text { DEPENDENT } \\
\text { VARIABLES }\end{array}$ & \multicolumn{3}{c}{$\begin{array}{c}\text { CONTROL } \\
(\mathrm{n}=23)\end{array}$} & \multicolumn{4}{c}{$\begin{array}{c}\text { EXPERIMENTAL } \\
(\mathrm{n}=25)\end{array}$} \\
\cline { 2 - 13 } & $\mathrm{X}$ & $\mathrm{SD}$ & $\mathrm{R}^{\circ}$ & $\mathrm{X}$ & $\mathrm{SD}$ & $\mathrm{R}^{\circ}$ & $\mathrm{U}$ & $\mathrm{Z}$ & $\mathrm{p}$ & $\mathrm{g}$ \\
\hline Planning & 1.12 & .33 & 23.92 & 1.17 & .38 & 25.13 & 273.0 & -.488 & .626 & .14 \\
\hline Predictions & 1.08 & .27 & 24.42 & 1.09 & .29 & 24.59 & 285.5 & -.086 & .931 & .04 \\
\hline Inferences & 1.04 & .10 & 23.46 & 1.13 & .36 & 25.63 & 261.5 & -1.121 & .262 & .33 \\
\hline Monitoring & 1.12 & .23 & 24.88 & 1.09 & .22 & 24.09 & 278.0 & -.370 & .711 & .13 \\
\hline Graphical R. & 1.08 & .27 & 23.38 & 1.21 & .51 & 25.72 & 259.5 & -1.007 & .314 & .31 \\
\hline Summary & 1.32 & .48 & 24.68 & 1.30 & .47 & 24.30 & 283.0 & -.116 & .908 & .04 \\
\hline Evaluation & 1.04 & .20 & 23.96 & 1.08 & .28 & 25.09 & 274.0 & -.664 & .506 & .16 \\
\hline Recall & 1.24 & .52 & 24.30 & 1.26 & .54 & 24.72 & 282.5 & -.146 & .884 & .03 \\
\hline
\end{tabular}

On the first posttest, significant differences were observed in favor of the experimental group on the strategies of planning $(U=136.5 ; p<.001)$ and predicting $(U=$ $129.5 ; p<.001)$. Likewise, the effect size on these variables is high. Although the experimental group presents a higher mean than the control group on the rest of the variables, these differences are not significant, and the effect size is low-moderate (see Table 8).

Table 8: Posttest 1. Between-groups comparison applying the Mann Whitney U test

\begin{tabular}{lcccccccccc}
$\begin{array}{l}\text { DEPENDENT } \\
\text { VARIABLES }\end{array}$ & \multicolumn{3}{c}{$\begin{array}{c}\text { CONTROL } \\
(\mathrm{n}=23)\end{array}$} & \multicolumn{3}{c}{$\begin{array}{c}\text { EXPERIMENTAL } \\
(\mathrm{n}=25)\end{array}$} & \multicolumn{3}{c}{ ASSOCIATED STATISTICAL VALUES } \\
\cline { 2 - 13 } & $\mathrm{X}$ & $\mathrm{SD}$ & $\mathrm{R}^{\circ}$ & $\mathrm{X}$ & $\mathrm{SD}$ & $\mathrm{R}^{\circ}$ & $\mathrm{U}$ & $\mathrm{Z}$ & $\mathrm{P}$ & $\mathrm{g}$ \\
\hline Planning & 1.18 & .43 & 18.46 & 1.78 & .59 & 31.07 & 136.5 & -3.581 & .000 & 1.14 \\
\hline Predictions & 1.16 & .37 & 18.18 & 1.80 & .60 & 31.37 & 129.5 & -3.768 & .000 & 1.25 \\
\hline Inferences & 1.28 & .54 & 21.38 & 1.69 & .82 & 27.89 & 209.5 & -1.901 & .057 & .58 \\
\hline Monitoring & 1.52 & .65 & 21.96 & 1.73 & .54 & 27.26 & 224.0 & -1.473 & .141 & .35 \\
\hline Graphical R. & 1.48 & .71 & 22.74 & 1.61 & .58 & 26.41 & 243.5 & -1.023 & .306 & .2 \\
\hline Summary & 1.36 & .63 & 22.20 & 1.52 & .52 & 27.00 & 230.0 & -1.384 & .166 & .27 \\
\hline Evaluation & 1.24 & .43 & 21.76 & 1.47 & .51 & 27.48 & 219.0 & -1.706 & .088 & .48 \\
\hline Recall & 1.68 & .80 & 22.66 & 1.86 & .69 & 26.50 & 241.5 & -1.024 & .306 & .24 \\
\hline
\end{tabular}


On the second posttest (Table 9), significant differences are observed on the means of all the reading comprehension strategies in favor of the group that followed the instructional material for developing strategies on reading tasks. Likewise, the effect size was large on half of the variables studied (planning, predictions, graphical representation and summary) and moderate on the rest of the variables (inferences, monitoring, evaluation and recall), which indicates that the instruction using the materials was effective in the majority of the students in the experimental group. Furthermore, while the control group presents a low level on narrative comprehension, the experimental group shows a medium level.

Table 9: Posttest 2. Between-groups comparison applying the Mann Whitney U test

\begin{tabular}{lcccccccccc} 
DEPENDENT & \multicolumn{3}{c}{$\begin{array}{c}\text { CONTROL } \\
\text { VARIABLES }\end{array}$} & \multicolumn{3}{c}{$\mathrm{n}=23)$} & \multicolumn{3}{c}{$\begin{array}{c}\text { EXPERIMENTAL } \\
(\mathrm{n}=25)\end{array}$} \\
\cline { 2 - 12 } & $\mathrm{X}$ & $\mathrm{SD}$ & $\mathrm{R}^{\circ}$ & $\mathrm{X}$ & $\mathrm{SD}$ & $\mathrm{R}^{\circ}$ & $\mathrm{U}$ & $\mathrm{Z}$ & $\mathrm{P}$ & $\mathrm{g}$ \\
\hline Planning & 1.38 & .66 & 17.66 & 2.28 & .83 & 31.93 & 116.5 & -3.777 & .000 & 1.17 \\
\hline Predictions & 1.48 & .71 & 19.80 & 2.13 & .84 & 29.61 & 170.0 & -2.623 & .009 & .82 \\
\hline Inferences & 1.40 & .70 & 21.18 & 1.90 & .86 & 28.11 & 204.5 & -1.963 & .050 & .62 \\
\hline Monitoring & 1.68 & .74 & 20.38 & 2.26 & .84 & 28.98 & 184.5 & -2.270 & .023 & .72 \\
\hline Graphical R. & 1.52 & .77 & 19.52 & 2.21 & .87 & 29.91 & 163.0 & -2.768 & .006 & .82 \\
\hline Summary & 1.64 & .70 & 19.18 & 2.35 & .83 & 30.28 & 154.5 & -2.912 & .004 & .91 \\
\hline Evaluation & 1.44 & .76 & 21.14 & 1.91 & .90 & 28.15 & 203.5 & -1.961 & .050 & .55 \\
\hline Recall & 1.76 & .83 & 20.52 & 2.30 & .82 & 28.83 & 188.0 & -2.185 & .029 & .64 \\
\hline
\end{tabular}

In summary, we can state that the program was effective in facilitating the internalization of the comprehension strategies and improving textual recall in the majority of the students.

\section{DISCUSSION}

The purpose of this article was to analyze whether students in the first grade of primary school who were taught using a direct instruction method improved their use of reading comprehension strategies and their text recall. In general, the results indicate that the students who were taught with the direct instructional approach obtained a higher level of comprehension strategies and text recall, 
compared to the group that followed a traditional methodology. Therefore, these results are consistent to a large degree with those from other studies that found that applying comprehension strategy programs at the lowest educational levels contributes positively to improving children's reading competence (e.g. Connor, et al., 2010; Eliers \& Pinkley, 2006).

However, it is also important to highlight that the application of this program has produced asymmetrical benefits in the students; i.e., certain students did not benefit from the program. Thus, and only in these cases, the results coincide with those obtained by Fuchs and Fuchs (2007), or with the conclusions of a review of intervention studies carried out by Rosenshine, et al., (1996).

Based on these results, we suggest that future research studies about reading comprehension in this population perform exploratory analyses of the baseline characteristics of the students (e.g. working memory, amount and level of vocabulary necessary during the application of the program, decoding and reading fluency, oral comprehension difficulties, Fuchs \& Fuchs, 2007). These data, along with information about the characteristics of the intervention context and the instruction program (e.g. training strategies, teaching modalities, duration, etc.), can lead to a more rigorous comparison between studies and help to better determine the benefits of these programs based on possible baseline profiles, in order to implement instructional programs that are better adapted to the specific needs of each student.

On the other hand, these results allow us to discuss the controversy about the development of metacognitive skills in childhood. The results from this study show that a large number of students who participated in the experimental instruction showed a certain degree of internalization of comprehension strategies. Therefore, the results obtained contribute positively to empirical and theoretical studies that indicate that metacognitive development and internalization of strategies depend to a certain degree on the educational context (e.g. Whitebread \& Basilio, 2012).

We are aware that the study design makes it difficult to conclude to what extent the improvement in reading performance was caused by: i) the internalization of the comprehension strategies; or ii) the interaction between a significant improvement in vocabulary acquisition, decoding and reading fluency, and the reading comprehension strategies, and other relevant variables. However, this design does contribute to the body of knowledge that poses questions like the following: Could improvement in reading competence benefit from instruction in comprehension strategies and text recall? Can the inclusion of instructional programs in the teaching-learning context influence individual differences in reading competence? Based on our results, and for our participants, the answer to these questions is yes; 
the prolonged application of an instructional program was extremely relevant in facilitating the internalization of learning strategies in the majority of the students, and in improving their reading performance.

Fecha de recepción del original: 7 de enero de 2013

Fecha de aceptación de la versión definitiva: 28 de junio de 2013

\section{BIBLIOGRAPHICAL REFERENCES}

Balcomb, F. K., \& Gerken, L. A. (2008). Three-year-old children can access their own memory to guide responses on a visual matching task. Developmental Science, $11,750-760$.

Bernad, J. A. (2000). Modelo cognitivo de evaluación educativa. Escala de estrategias de aprendizaje contextualizado (ESEAC). Madrid: Narcea.

Block, C. C., Pressley, M. (2002). Comprehension instruction: Research-based best practices. New York: Guilford Press.

Block, C., Parris, S., \& Whiteley, C. (2008). CPMs: A kinesthetic comprehension strategy. The Reading Teacher, 61(6), 460-470.

Booth, J. N., Boyle, J., \& Kelly, S. (2010). Do tasks make a difference? Accounting for heterogeneity of performance of children with reading difficulties on tasks of executive function: Findings from a meta-analysis. British fournal of Developmental Psychology, 28(1), 133-176.

Brenna, B. A. (1995). The metacognitive reading strategies of five early readers. Fournal of Research in Reading, 18(1), 53-62.

Bronson, M. B. (2000). Self regulation in early childhood: nature and nurture. New York: The Guilford Press.

Brown, R., Pressley, M., Van Meter, P., \& Schuder, T. (1996). A quasi-experimental validation of transactional strategies instruction with low-achieving second grade readers. Fournal of Educational Psychology, 88, 18-37.

Bull, R., Espy, K. A. \& Wiebe, S. A. (2008). Short-term memory, working memory, and executive functioning in preschoolers: longitudinal predictors of mathematical achievement at age 7 years. Developmental Neuropsychology, 33(3), 205-28.

Cartwright, K. B. (2012). Cognitive development and reading: The relation of reading-specific multiple classification skill to reading comprehension in elementary school children. Fournal of Educational Psychology, 94, 56-63.

Chall, J. S. (1967). Learning to read: The great debate. New York: MacGraw Hill.

Chall, J. S. (1996). Stages of reading development. Orlando, L: Harcourt Brace Company. 
Cohen, J. (1988). Statistical power analysis for the behavioral sciences. Hillsdale: Erlbaum.

Connor, C. M., Ponitz, C. C., Phillips, M. B., Travis, Q. M., Glasney, S., Morrison, F. J. (2010). First graders' literacy and self-regulation gains: The effect of individualizing student instruction. Fournal of School Psychology, 48(5), 433-455.

Dermitzaki, I., Andreou, G., \& Paraskeva, V. (2008). High and low reading comprehension achievers' strategic behaviors and their relation to performance in a reading comprehension situation. Reading Psychology, 29, 471-492.

Dignath, C., Buettner, G., \& Langfeldt, H. P. (2008). How can primary school students learn self-regulated learning strategies most effectively? a meta-analysis of self-regulation training programmes. Educational Research Review, 3(2), 101-129.

Dole, J. A., Nokes, J. D., \& Drits, D. (2009). Cognitive strategy instruction. In G. G. Duffy \& S. E. Israel (Eds.), Handbook of research on reading comprehension, 347-372. Hillsdale: Erlbaum.

Efklides, A., \& Misailidi, P. (2010). Trends and prospects in metacognition research. New York: Springer.

Eilers, L. H., \& Pinkley, C. (2006). Metacognitive strategies help Students to comprehend all texts. Reading Improvement, 43, 13-29.

Ellis, P. D. (2009). Effect size calculators. Extraído el 1 de abril de 2013 de http://www.polyu.edu.hk/mm/effectsizefaqs/calculator/calculator.btml

Eme, E., Puustinen, M., Coutelet, B. (2006). Individual and development differences in reading monitoring: When and how do children evaluate their comprehension? European Fournal of Psychology of Education, 21, 91-115.

Flavell, J. H. (1987). Speculations about the nature and development of metacognition. In F.E. Weinert \& R.H. Kluwe (Eds.), Metacognition, Motivation and Understanding (pp. 21-29). Hillsdale: Erlbaum.

Fernández-Cano, A., \& Fernández Guerrero, I. (2009). Crítica y alternativas a la significación estadística en el contraste de hipótesis. Madrid: La Muralla.

Fuchs, D., \& Fuchs, L. S. (2007). Increasing strategic reading comprehension with Peer-Assisted Learning Strategies. In D.S. McNamara (Ed.), Reading comprehension strategies: Theories, interventions, and technologies (pp. 175-197). Mahwah: Erlbaum.

Garner, J., Bochna, C. (2004). Transfer of a listening comprehension strategy to independent reading in first-grade students. Early Childhood Education Fournal, 32(2), 69-74.

Gutiérrez-Braojos, C., \& Salmerón-Pérez, H. (2012). Estrategias de comprensión lectora: enseñanza y evaluación en educación primaria. Revista Profesorado, 16(1), 183-202. 
Horner, S. L., \& O'Connor, E. A. (2007). Developing self-regulation within the reading recovery context. In S. L. Horner \& E. A. O'Connor (Eds.), Helping beginning of struggling readers and writers develop self-regulated strategies. Special issue of Reading and Writing Quarterly, 23, 97-106.

Juliebö, M., Malicky, G., \& Norman, C. (1998). Metacognition of young readers in an early intervention programme. Fournal of Research in Reading, 21(1), 24-35.

Kendeou, P., van den Broek, P., White, M. J., Lynch, J. S. (2009). Predicting reading comprehension in early elementary school: The independent contributions of oral language and decoding skills. Fournal of Educational Psychology, 101(4), 765-778.

Kinnunen, R. Vauras, M., \& Niemi, P. (1998). An interview study of children s knowledge about memory. Monographs of the Society for Research in Child Development, 40, 1-160.

McKeown, M. G., \& Beck, I. L. (2009). The role of metacognition in understanding and supporting reading comprehension. In D.J. Hacker, J. Dunlosky, \& A.C. Graesser. Handbook of Metacognition in Education. New York: Routledge

Marr, M. B., \& Gormley, K. (1982). Children's recall of familiar and unfamiliar text. Reading Research Quarterly, 18, 89-104.

Mayer, R. E. (2002). Psicología educativa. Madrid: Prentice-Hall.

National Reading Panel (2000). Teaching children to read: An evidence-based assessment of the scientific research literature on reading and its implications for reading instruction. Extraído el 2 de abril de 2013 de http://www.nichd.nih.gov/ publications/nrp/report.cfm

National Research Council (1998). Preventing reading difficulties in young children. Washington: National Academy Press.

Paris, S. G., \& Hamilton, E. E. (2009). The development of children's reading comprehension. In S. E., Israel \& G. G., Duffy. Handbook of research on reading comprehension (pp. 32-53). New York: Routledge.

Paris, A. H., \& Paris, S. G. (2003). Assessing narrative comprehension in young children. Reading Research Quarterly, 38, 36-76.

Paris, A., \& Paris, S. G. (2007). Teaching narrative comprehension strategies to first graders. Cognition and Instruction, 25(1), 1-44.

Paris, S. G., Wasik, B. A., \& Turner, J. C. (1991).The development of strategic readers. In R. R. Barr, M. L. Kamil, P. Mosenthal, \& P. D. Pearson (Eds.), The bandbook of reading research (Vol. 2, pp. 609-640). New York: Longman.

Pearson, P. D. (2009). The roots of reading comprehension instruction. In S.E. Israel \& G. G. Duffy (Eds.), Handbook of research on reading comprehension (pp. 331). New York: Routledge. 
Pearson, P. D., \& Duke, N. K. (2002). Comprehension instruction in the primary grades. In C. C. Block \& G. M. Pressley (Eds.), Comprehension instruction: Research-based best practices (pp. 247-258). New York: Guilford Press.

Pearson, P. D., \& Gallagher, M. (1983).The instruction of reading comprehension. Contemporary Educational Psychology, 8, 317-344

Ponitz, C. C., McClelland, M. M., Jewkes, A. M., Connor, C. M., Farris, C. L., \& Morrison, F. J. (2008). Touch your toes! Developing a direct measure of behavioral regulation in early childhood. Early Childhood Research Quarterly, 23, 141-158.

Pressley, M., \& Block, C. C. (2002). Summing up: What comprehension instruction could be? In C. C. Block \& M. Pressley (Eds.), Comprehension instruction: Research-based best practices (pp. 383-392). New York: Guilford Press.

Rosenshine, B., \& Stevenes, R. (1986). Teaching functions. In M.C. Wittrock (Ed.), Handbook of Research on teaching (pp. 376-391). New York: MacMillan.

Rosenshine, B., Meister, C., \& Chapman, S. (1996). Teaching students to generate questions: A review of the intervention studies. Review of Educational Research, 66, 181-221.

Ruplay, W. H., Blair, T. R., \& Nichols, W. D. (2009). Effective reading instruction for struggling readers: The Role of Direct/explicit Teaching. Reading \& Quarterly, 25(2), 125-138.

Sesma, H. W., Mahone, E. M., Levine, T., Eason, S. H., \& Cutting, L. E. (2009). The contribution of executive skills to reading comprehension. Child Neuropsychology, 15, 232-246.

Smith L. E., Borkowski J. G., \& Whitman T. L. (2008). From reading readiness to reading competence: The role of self-regulation in at-risk children. Scientific Studies of Reading, 12, 131-152.

Strasser, K., \& Lissi, M. R. (2009). Home and instruction effects on emergent literacy in a sample of Chilean kindergarten children. Scientific Studies of Reading. 13, 175-204.

Taylor, B. M., Peterson, D. S., Pearson, P. D., \& Rodriguez, M. C. (2002). Looking inside classrooms: Reflecting on the "how" as well as the "what" in effective reading instruction. The Reading Teacher, 56(3), 270-279

van den Broek, P., Kendeou, P., Kremer, K., Lynch, J., Butler, J., White, M. J., \& Lorch, E. P. (2005). Assessment of comprehension abilities in young children. In S. G. Paris \& S. A. Stahl (Eds.), Current issues in reading comprehension and assessment, (pp. 107-130). Mahwah: Erlbaum.

Veenman, M. V. J., \& Spaans, M. A. (2005). Relation between intellectual and metacognitive skills: Age and task differences. Learning and Individual Differences, 15, 159-176. 
Vygotsky, L. S. (1978). Mind in society. The development of higher psychological processes. Cambridge: Harvard University Press.

Welsh, J. A., Nix, R. L., Blair, C., Bierman, K. L., \& Nelson, K. E. (2010). The development of Cognitive skills and gains in academic school readiness for children from low income families. Fournal of Educational Psychology, 102, 43-53.

Whitebread, D., \& Basilio, M. (2012). Emergencia y desarrollo temprano de la autorregulación en niños preescolares. Revista Profesorado, 16(1), 1-34.

Winne, P. H., Graham, L., \& Prock, L. (1993). A model of poor readers text-based inferencing: Effects of explanatory feedback. Reading Research Quarterly. 28(1), 52-66. 